How might social education resist (hetero)sexism?

Facing the impact of gender and sexual ideology on citizenship

\title{
Published in Theory and Research in Social Education
} vol.30 no.2 (Spring), 2002

Kathy Bickmore, Ph.D.

Ontario Institute for Studies in Education, University of Toronto

kbickmore@oise.utoronto.ca

Abstract: This paper examines the mutually-reinforcing problems of sexism and heterosexism, and the actions that may be taken by social educators to ameliorate such injustices. Various approaches to anti-heterosexism education are organized in relation to the three dimensions of handling social conflict: intervention procedures (in particular the management of sexual and heterosexist harassment), teaching knowledge and skills (in particular skills for recognizing the role of gender and sexuality in culture and for managing controversy), and restructuring patterns of relationship (in particular reducing the climate of heteronormativity and status competition that exacerbate harassment and exclusion).

What do sexism and heterosexism have to do with social and citizenship education? Everything. A person's gender and intimate relationships are crucial elements of their membership and roles in society. People care so much about gender that 'Boy or girl?' is typically the first question asked about a new baby. The ideologies surrounding sexuality and gender have shaped human social interaction spatially (for instance housing patterns reflecting different sizes and types of families) and politically (for instance the influence of a person's 'private life' on their chance to serve in government or the military), across history. The overlapping problems of sexism and heterosexism reflect the social conflicts embodied in the inequitable distribution of power between males and females, and between majority sexual identities and minorities. Social identity (diversity and membership), social conflict (decision making and governance in the context of pluralism), and justice (contested rights and protections) are core elements of democratic citizenship. Sexism and heterosexism, and their underlying gender and sexual ideologies, highlight these core elements of citizenship and thus provide a valuable (and often missed) learning opportunity for social education. To ignore these concerns is to reinforce dominant exclusionary ideologies.

This paper examines various aspects of social education that may reinforce - or resist- (hetero)sexism. There are three dimensions of managing any social conflict, all of which apply to the problem of (hetero)sexism (see Diagram 1). These dimensions will serve to organize the paper:

- intervention: practices and procedures for managing conflict and violence, during and after visible incidents

- teaching: knowledge and skill development for managing problems, aimed at preventing violence, harassment and discrimination

- restructuring: changing patterns of interaction to build equitable, resilient relationships in inclusive nonviolent climates 
The first dimension emphasizes control, in this case the effort to prevent or minimize sexual and heterosexist harassment and related violence. Because violence is such an obvious human rights violation, and because of schools' tendency toward using rule enforcement to keep the lid on problems, this is probably the most common school response to heterosexism, when there is any (conscious) response at all. The fact that gender equity and especially sexual diversity are considered controversial issues tends to constrain the second and third dimensions. Thus the concepts and skills we teach are often partial: Social educators may teach about conflict resolution or bullying or women's contributions to history in a generic manner, and yet ignore underlying inequity problems such as sexism and heterosexism. The third dimension is the broadest and not amenable to quick fixes, but again there are things schools already may be doing (such as reducing competition or helping diverse students to get to know one another) that are relevant to this dimension of social conflict management. After a brief look at the context from which we begin — what students are already learning about gender and sexual identity from schools and societies - we will look at how social education may reinforce and/or resist heterosexism, in each of these three interwoven categories of activity.

\section{Starting points: what do children know about sexuality?}

Students are hardly blank slates: they typically have both knowledge (not necessarily correct) and concern about sexual identity matters by early elementary school. Information and misinformation about sex and gender relations flow freely these days in public spaces, media, and peer groups. Sexuality is present and visible, although often unremarked, in the public images experienced by virtually all youth in the western world. One can hardly avoid seeing people kissing, dancing or dressing in ways designed to be sexually attractive, celebrating marriages, and so forth. Political campaigners, entertainers, television and movie narratives, comic strips, and billboard advertising present powerful models regarding which members of a society, and which kinds of intimate relationships, are valued (Adams 1997, Epstein \& Johnson 1998, Ortner 1996). Most North American children and youth have heard words such as 'gay' used as slurs, whether or not they know their definitions (Chasnoff \& Cohen 1997). Children also generally know that they risk being teased and hurt if they are known to live in unusual families (R. Epstein 1998). By middle school, girls and boys have learned to define their gender identities in large part by heterosexual behavior: they generally believe that a girl 'must' have or seek a boyfriend, and a boy 'must' have a girlfriend or seek sexual relations with girls, and they know they will be tormented if they do not conform (Harris \& Bliss 1997, Mandel 1996). In this age of mass popular culture, the assumption that adults can and should keep certain information away from children is outdated (Adams 1997, Elkind 1995).

Within the formal social studies curriculum, the supposedly-neutral language used in textbook narratives and graphics carries a gendered and sexualized point of view, all the more powerful where unremarked. Most characters in human dramas and societies (thus in literature and social studies) have gender identities and intimate relationships.

It is impossible ... to teach almost any piece of literature without transgressing onto the field of sex education. ... Similarly, imagine biology without human reproduction, geography without population studies ... or religious education without a consideration of the roles of men and women. (Reiss 1995, 374) 
The vast majority of literature used in school generally avoids explicit (or affirmative) mention of homosexuality (Apostol 1998, EGALE 1998). However, it does quietly include sexuality in the form of normalized nuclear families and heterosexual relationships. Tuula Gordon and her colleagues give a vivid example from their classroom research: in a lecture on South African history, a teacher told the class, "Boers took their wives and children with them" (Gordon et.al. 2000a, 193). People often don't notice the sexuality in these images because they assume as 'common sense' history's emphasis on male protagonists in heterosexual, married, male-dominant nuclear families.

The recent surge of highly visible homophobic intolerance and violence has itself brought sexual identity to the surface of public consciousness (Aronson 1994, Giese 1998). The mass media play an important part in over-simplifying and polarizing potentiallycontroversial issues such as those involving sexual identity. While an original news report may attempt to provide some balance and context regarding an emergent concern or issue, subsequent recirculated coverage tends to emphasize the most extreme aspects of the original story. For example, media lambasted the New York State 'Rainbow' curriculum reform after somebody discovered, and reported out of context, that 3 (of 600 plus) books in the curriculum's recommended bibliography presented homosexual characters in a favorable light. Such sensationalism helps "to fan the flames of homophobia, and convince lots of 'people in the middle' to adopt the New Right's point of view" (Fine 1995, 168). Where controversies about sexual identity are unprobed and unquestioned, not discussed in social studies class, they are particularly vulnerable to inaccuracy and bigotry.

Thus the question is not really whether to address gender and sexuality in social studies class, since they are already present in the textbooks and in the ideas, concerns, and behavior patterns students bring with them to school. The important question is how to help students learn to critically filter and to apply the information that surrounds them. First, we will look at the intervention dimension - teachers' and schools' responses to sexual bullying and harassment, the most visible manifestations of heterosexism in schools. Second, in considering the knowledge and skill (teaching) dimension, we will examine the practice of citizenship education (regarding controversy, inclusion, gender and sexuality). Last, we will consider the broad dimension of citizen relationships and the school structures that help to (re)form them - expectations for gendered and sexual behavior and the associated rights and protections, in the context of diverse school communities.

\section{Handling sexual/ homophobic harassment}

Teachers and schools model and practice approaches to sexual identity and diversity in the ways they handle gender-biased and homophobic behavior when it arises. Harassment is a form of bullying reinforced by bias: people who are more powerful attempt to intimidate, control, or deny human rights to people who are less powerful. Sexual harassment, in particular, takes advantage of the power inequities embedded in sexism and homophobia to target females and some males.

Sexual harassment is any unwanted or uninvited remarks, gestures, sounds or actions of a sexual nature that makes one feel unsafe, degraded or uncomfortable. It creates an intimidating, hostile, and offensive school environment (Ball \& Martyn 1999, 20) 
Harassment, especially among young people in schools, is often public action (for example loud behavior in front of peers or visible grafitti) that gains the harassers status or acclaim among their peers, while exposing and reducing the status of their targets (Shakeshaft \& Mandel 1997, Stein 1995). Students and sometimes teachers are targeted because of their presumed membership in certain gender or sexual categories, especially if they look or act in ways that seem to transcend or challenge dominant community norms of gendered behavior.

Bullying is (hetero-)sexualized because of the power this social inequity confers upon the bullies; for the same reason, sexual harassment quite often incorporates racist slurs and stereotypes (Duncan 1999, Larkin \& Staton 1998). Heteronormativity, or 'compulsory heterosexuality,' is an ideology that encourages and enforces norms of heterosexual behavior, creating a climate that encourages gay- and lesbian-bashing, heterosexist teasing, and harassment (McCaskell 1999, Mlamleli et.al. 2000, Rich 1979). Homophobia is fear and hatred of homosexuality, which can be particularly damaging when internalized as selfhatred, leading at times even to suicide (Portner 2001). Sexual (including heterosexist) harassment is a strategy for continually defining, defending, and embodying a hegemonic version of masculinity that incorporates heterosexuality and rejects homosexuality and femininity (Bender 2001, Connell 1995, Frank 1986). In a recent survey, about $70 \%$ of 900 lesbian, gay, bisexual and transgender youth reported feeling threatened at school, due to harassment in relation to their sexual identity (GLSEN 2001).

Harassment is a 'weapon' used for maintaining strict gender boundaries through peer pressure (Pharr 1988). Calling somebody gay or lesbian is meant as an insult — not necessarily referring to homosexuality, per se, but to social rejection based on supposedlybreached boundaries of dichotomized 'male' or 'female' behavior (Lees 2000). Thus teachers' and schools' choices in managing the problem of harassment can influence the breadth and permeability of those boundaries. Harassment would not work to shore up harassers' power unless the sexual and heteronormative ideologies that underlie harassment were generally agreed upon and affirmed by the (school or classroom) culture.

Intervention procedures for handling harassment problems may range from short-term control measures, such as punishment or exclusion of perpetrators, to more in-depth problemsolving measures such as awareness discussions or group conferencing. The most common institutional response to harassment in recent years has been the 'zero tolerance' crackdown, which has astronomically increased the rates of school exclusion via suspensions and expulsions in many school districts (Dalton 2000, Harrington 1999). Harassment has been labeled and criminalized, focusing on punishing perpetrators and, to some extent, on protecting (presumed passive) victims. While conflict management procedures are evidently necessary for handling harassment after it occurs, they are by themselves insufficient because they do not teach individuals or groups how (or why) to understand gender and sexual diversities differently or to behave nonviolently. At the same time, because students are adept at hiding behavior from their teachers and because prevailing ideologies accept sexual teasing as normal, most sexual (including heterosexist) harassment persists unabated in spite of sometimes punitive climates (McCaskell 1999, Scott 1995). To be effective, any intervention effort would need to address the sexism and heterosexism that give school-based harassment its power and persistence.

An overly competitive school environment can exacerbate problems of heterosexist violence. In the eyes of students, many schools ignore and/or implicitly condone taunting 
and harassment, and encourage the social status competition that nurtures such abuse (McDonald 1996, Stein 1995, Wessle 2000). For example, a popular member of Columbine High School's football team, describing peers' treatment of the two students who got upset enough to murder several of their classmates, demonstrates how completely he had learned and acted upon his intolerance and imagined superiority:

Columbine is a good clean place except for those rejects. Most kids didn't want them there. ... Sure we teased them. But what do you expect, with kids who come to school with weird hairdos and horns on their hats? ... If you want to get rid of someone, usually you tease 'em. So the whole school would call them homos... (quoted in Time magazine, reprinted in Aronson 2000, 71-72)

Clearly short-term or punitive interventions focusing on the symptoms of harassment would not, alone, do much to prevent violence in such a situation. When a social environment fosters a climate of rejection, and encourages feelings of superiority among some at the expense of others, harassment will inevitably flourish. Setting limits that criminalize and/or pathologize abusive behavior seems like common sense, and it is a relatively easy reform for (already rule-oriented) schools to implement. However, control is not education, and such strategies are unable to address the social conflicts and conditions that encourage harassment.

\section{Teaching knowledge and skills for inclusion and problem solving}

A second dimension of handling heterosexism is knowledge and skill development, so that students and teachers recognize and handle harassment and the underlying social as well as interpersonal inequities and conflicts. Management of any conflict (and thus democratic citizenship) depends on knowledge and skills such as: verbal and non-verbal communication, forging relationships, analyzing sources of power, recognizing common and divergent interests, negotiation, problem analysis, creative invention of solution ideas, and making decisions. The more complicated area of (hetero)sexual harassment depends, in addition, on an understanding of sexism and heterosexism, and a capacity to identify and respond to power imbalances and peer pressure toward 'normalcy.' All of this knowledge is relevant to a range of social studies coursework, and can be developed in that context (Bickmore 1996, 1999a, 1999b).

Anti-harassment education in schools is intended to 'empower' youth by giving them skills and information with which to make responsible choices. This, of course, implies agency and responsibility on the part of the participants in harassment activity. In theory at least, such a program could build skills and awareness without falling into the pitfall of some anti-bullying and sex education programs, which implicitly expect the targets of pressure or abuse (those most motivated to learn avoidance strategies) to take the primary responsibility for setting limits. This over-emphasis on fixing the victim "naturalizes violence endured by women [and sexual minorities] by portraying it as resulting from their lack of character or aptitude" (Luschen 2001, p. 123). This emphasis on re-educating targets is no more palatable as an exclusive program focus than the 'zero tolerance' emphasis on punishing selected perpetrators.

It is not primarily the 'abnormal' individuals being targeted by heterosexism, harassment, or other social exclusion who most need to learn new concepts and skills. Those who are 'put down' virtually always know more than the 'ups' about the social difference 
and inequity problem that has occasioned their oppression. Rather, it is the broad membership of their groups - especially bystanders and potential allies - who must become unaccustomed to excluding certain individuals from shared space.

[An elementary classroom is the child's] first real exposure to the public arena. ... Within this public space a new concept of open access can develop if we choose to make this a goal. ... In general, the approach has been to help the outsiders develop the characteristics that will make them more acceptable to the insiders. I am suggesting something different: the group must change its attitudes and expectations toward those who, for whatever reason, are not yet part of the system (Paley 1992, 21 \& 33, emphasis in original).

Any change in the patterns of heterosexist domination will require the whole group, not just the targets of discrimination, to revise and broaden their expectations regarding gender and sexual diversity, because these are entwined in everybody's practice of social exclusion and citizenship.

On the other hand, both sexuality education and anti-violence education often have been used as instruments of social control — defining 'appropriate' and 'deviant' behavior and obscuring many of the most important issues behind generic no put-down rules or rarified terminology (Lees 2000, Sears 1992). These kinds of education, designed to 'fix' social problems, have tended to expand adults' surveillance and control over young people -for example, publicly airing topics and soliciting information once relegated to the private realm - without necessarily addressing the social structural roots of the problems (Schissel 1997, Wyness 2000). It would be ironic for democratic citizenship education to proceed too far in this direction. Social education needs to balance (on one hand) empowering students with meaningful knowledge and skills, giving them some individual agency, with (on the other hand) taking adult responsibility to set reasonable limits, to help alleviate power imbalances and abuse.

Although teachers often are not given much latitude to teach about sexuality, they are often held responsible when education 'fails' to alleviate such sexuality-related problems as the spread of AIDS (e.g. Infantry 1998). The common assignment of sexuality education to physical/ health education, rather than social studies, may exacerbate the tendency of educators to emphasize abstract clinical information rather than human diversity, social justice, and democratic principles. There is no evidence that open or explicit sexuality education leads to increased sexual behaviour of any kind: on the contrary, either it has no significant effect or it is associated with safer sexual practices and postponement of sexual activity (Epstein \& Johnson 1998, 172; Lenskyj 1990, 219; Reiss 1995, 375). Since the topic is so often censored, we don't have similarly robust evidence regarding the consequences of homosexuality education. However, it makes sense: Giving children concepts, vocabulary and strategies for handling gender role questions and homosexuality is likely to help them to resist homophobic ignorance, to avoid unsafe practices, and to treat themselves and others respectfully (Rofes 1995). A child's reading about or discussing any belief or culture in school has never been shown to cause them to adopt that way of life (Gutmann \& Thompson 1996, 66).

Simply including the occasional sexual minority person in the curriculum is not sufficient to address the problem of heterosexism, although it can be a place to begin. As 
Noddings shows, the important question is what range of perspectives and opportunities for critical thought might be presented, not merely whether a token woman (or an open member of a sexual minority) is mentioned:

[Emily Greene Balch, a feminist pioneer in working for international peace] is now included in standard texts, but the power and significance of her work, her point of view, her culture are all still hidden (Noddings 1992, 234).

An curriculum for equity would examine and compare genuinely diverse points of view, in order to develop "the vital political skills required to challenge gender and class relations" (Davies 2000, 294).

When brought out into the light of the explicit curriculum, gender role socialization and the accompanying (de)valuation of (homo)sexual identities are clearly unsafe terrain for teachers. The news carries recurring scandals in which individual teachers are targeted for saying too much about sex, or for allowing young people to read about homosexual people. Often teachers who choose to raise the matter of homosexuality are presumed to be homosexual, and are thereby at risk of job loss. There are institutional remedies for this insecurity, to be discussed in the next section.

Sexual pluralism is not the kind of controversial issue that can (or should) be easily dichotomized. Social studies teachers who address public issues, as well as most North American news sources, tend to favor simplified pro-or-con questions (Tannen 1998). As with other matters of social rejection/exclusion, it is both important and difficult (in the context of the polarized attacks common in public discourse) to frame the relevant questions in ways that do not infringe on the human rights and dignity of individuals. In contrast, matters of policy, such as how to dispose of municipal garbage or whether to penalize alcohol possession, can often easily enough be framed in two-sided terms (although even here, as Tannen shows, dichotomies do not necessarily improve understanding or the potential for problem solving). Sexuality and homosexuality are controversial, but there is no defensible simple 'anti' position, since homosexuality exists in all human societies and the health and safety of real people (targeted by heterosexism) are at stake.

Many teachers' avoidance of sexual identity topics is influenced less by fear of political controversy or censorship than by the challenge of teaching any conflictual topic. The increasing pressures of curriculum accountability make some teachers averse to risking deeply-meaningful subject matter, such as human relationships and sexuality, because these might open unpredictable avenues for learning and thus not efficiently meet narrow shortterm objectives. In striving for comfortable classroom environments and high achievement scores, many teachers avoid vital issues. As a result, students and teachers often consider social studies to be unimportant and uninteresting; thus they miss out on learning that might help them to develop into empowered democratic citizens (Bickmore 1993, 1997, Hahn 1996, Houser 1996). Discussing controversial material such as sexual identity issues with young students is risky, but it is incredibly important to their personal and political development.

If we are to have consent in a democratic people it must be built upon the study of controversial issues, because such study is the intellectual foundation of the schools. ... How else can human beings practice decision making than 
by confronting issues? (Harold Rugg 1941, quoted in Fine 1995, 109)

This is a challenge that good teacher education, and institutional support for teachers in schools, districts, and unions, can help to solve.

As they grow up, children gain the power to protect themselves by learning to acquire and evaluate knowledge, not by being denied information. Young people's self-determination as citizens, and their respect for the self-determination of others, depends on their opportunities to learn to handle difficult questions and contrasting viewpoints, to correct their misunderstandings, and to get along with diverse others in their communities. Carefullydesigned education about sexuality, including homosexuality, can provide such an opportunity. Instead of trying vainly to protect young children from the discomforts of learning difficult knowledge, teachers can gently "invite [students] into the ongoing predicament" of a world that includes troubles such as homophobia (Ellsworth 1997, p. 24). Education that emphasizes the imperfect relationships among women and men, including their mutual responsibilities and the social structures of unequal power that help to shape their individual choices, is good social studies and good citizenship education.

\section{Rights and relationships: the on-going practice of gendered and sexual citizenship}

The relationships that are nurtured in the school and classroom context are the third important element in the development of an equitable nonviolent climate. Relationships are not merely interpersonal; they are framed by prevailing ideologies, in-groups and out-groups, and the concrete ways in which rights may (or may not) be protected within the institution. Gay, lesbian, bisexual and transgender human rights provide interesting and troubling cases for both social education learning and school reform, because these rights are still so unevenly supported (Donahue 2000, Osler \& Starkey 1998).

Educators operate within murky and moveable social and political boundaries. Teachers who wish to teach inclusivity "are in a terrible bind - they can either ignore children's often dangerous misinformation, or step in and address it and be censured" (Giese 1998, p. A13). Most censorship in schools is self-censorship by the teachers themselves (Hydrick 1994). In response to their own sense of students' prior knowledge and maturity, or in anticipation of parents' or principals' potential objections, teachers often avoid practicing democratic foundations such as free expression and access to information.

School, district, and province or state-level rights protections can make an important difference in defining at least a basic threshold of safety, to limit this climate of silencing. Where official guidelines 'require' all teachers to cover sexual and homosexual topics, they lower the risks of dealing with such controversial material (Khayatt 1997). A school board equity policy that does not protect sexual preference creates a chilly climate for antihomophobia instruction. Human rights legislation that does include sexual orientation creates a warmer climate for discussions of homosexuality and a safety net for teachers who do so. It is surely much easier to teach children accepting attitudes toward gender and sexual identity where their school contexts label and limit bullying, gender-based harassment, and heterosexist targetting of teachers and students (Lenskyj 1990). Teachers unions, too, could provide better protection for members who air potentially-unpopular viewpoints. Unfortunately, the National Education Association recently backed away from considering a resolution "encouraging schools to develop curriculum to support lesbian, gay, bisexual and transgender students and staff" (Associated Press 2001 [note: a Feb. 2002 decision may have 
reversed this action]). The fact that protection of sexual diversity is (sometimes) on the agenda is probably an improvement over unspeakability, but (as discussed earlier) often the ways such controversies are raised can make the climate even more unsafe for sexual minorities.

Students can be extraordinarily creative and courageous in addressing matters of sexual identity themselves, especially where their rights to do so are protected by adult staff members. For example, a high school student newspaper in a suburb of Austin, Texas published a 5-page section presenting a carefully-considered range of opinions regarding homosexuality, as the first item in a series on accepting diversity at their school (Teaching Tolerance 1994). The newspaper's faculty advisor and school administration stood by the young journalists in the face of antagonistic criticism fomented by a radio talk show, weathering the storm and eventually winning an award from the National Scholastic Press Association. Advisor Deanne Kunz explains:

Students today report that their worries extend beyond the usual college and career choices to encompass such concerns as pollution and sexually transmitted diseases, school violence and neighborhood crime. We feel that a school newspaper should address these issues and that student journalists should report on sensitive topics. As their advisor, I wanted students to feel empowered to make tough editorial decisions. ... And while we have been reminded that standing up for one's beliefs can lead to controversy, we have also learned that controversy itself can be an educational experience.

(Teaching Tolerance 1994, 26)

Other important student and co-curricular initiatives that require teacher and school support include advocacy and support groups, often known as Gay-Straight Alliances, springing up in many schools across the United States and Canada. Such groups have provided sufficient support so that students who had dropped out due to harassment could reenter school, as well as educating peers regarding homophobia and sexual identity (Canadian Press 2000). Motions to support such organizations have encountered polarized opposition, as well as support at various teachers federation (union) meetings (Associated Press 2001, Canadian Press 2000). In another instance, a school-based peer mediation program advisor recently described the difficulty she had in giving an openly-gay male student the opportunity to serve as a mediator, and the way the student mediation team eventually came around to an inclusive stance (Cohen 2001). Young people often have a breathtaking capacity to overcome their biases, given the opportunity and some personal and/or institutional support.

Opportunities for restructuring school citizenship space are by no means limited to the whole-school or co-curricular arena. Perspective-taking ability and empathy (prerequisites for reducing bias and violence) can be developed through practice, for example by allocating time for thoughtful deliberation regarding controversial issues and through regular work in constructively interdependent cooperative learning groups.

You don't get students from diverse backgrounds to appreciate one another by telling them that prejudice and discrimination are bad things. You get them to appreciate one another by placing them in situations where they interact with 
one another in a structure designed to allow everyone's basic humanity to shine through. (Aronson 2000, p.171).

Teachers and other school leaders can create less competitive and more inclusive climates by replacing individualistic competition and a laissez-faire approach to exclusion with regularlystructured opportunities to examine and apply multiple perspectives in cooperative settings. In the process, we create space for the development of non-harassment contexts and democratic capabilities (Avery et.al. 1997, Bergsgaard 1997, Bickmore 1996, 1999b). Similarly, social educators can present frequent structured opportunities for overcoming ignorance and intolerance of sexual diversity, if we have the courage to approach this messy controversial topic openly and to systematically protect the expression of human and democratic rights.

\section{Conclusion}

Like any social identity, sexual identity is socially and institutionally constructed: it is not reducible to a stable individual attribute. Labeling some people as 'straight' and others 'queer,' or assuming that sexual diversity is only a problem for gay and lesbian people, is inaccurate and misleading. Understandings of self, others, and human differences are continually reconstructed in light of specific social interactions and power relations (e.g. Roy 1994). Among children and adolescents, these identity reconstructions can be especially fluid. Schools and social educators facilitate this process of differentiation, steering students toward certain identities and behaviors and away from others, but they do not do so seamlessly (Gordon et.al. 2000b). The complex intersections and contradictions among school practices regarding sexual identity leave spaces for people to make a difference - to resist aspects of heterosexism and intolerance and to broaden citizenship inclusion where possible.

Put in another way, sexual identity and bias implicate all of us, not just those who may be currently designated as different. We all play a part in reinforcing or resisting 'masculinity.' To affirm hegemonic masculinity as it is typically understood and practiced (as heterosexual conquest and the capacity to be violent) is to impede the inclusion and participation upon which democracy depends (Davies 2000). We all play a part in opening or closing the citizenship gate, defining in practice who is included in 'us.'

Citizenship education has never totally been the stabilizing force that its more conservative advocates have hoped it would be. Like education itself, it was and is an arena in which competing beliefs and interests meet. As historians remind us, the rights of citizenship have not just grown of their own volition, nor have they simply been handed down from on high. They are the result of struggle and conflict. ... Indeed, the most important purpose citizenship education should serve is to introduce students to the questions that lie at the heart of Canadian [or any] citizenship, give students the knowledge to understand them, the skills to pursue them, and the values and dispositions to do so in ways that respect the processes and commitments of democracy. (Osborne 2000, 9)

The questions that lie at the heart of citizenship include the social conflicts surrounding 
sexual identity and pluralism - how gender and sexual ideologies have shaped the societies we know, as well as how inclusivity may be protected and rejection rejected. Anti-

harassment interventions are a part of the education toward such citizenship, because such protection of human rights is a model and practice of inclusion. Classroom teaching can help students (and ourselves!) to develop more complex and inclusive understandings of sexual identity and (hetero)sexism as well as skills for handling a wide range of social conflicts, but not without opening the agenda to include the occasional controversial topic. Restructuring interaction patterns in schools and classrooms toward resisting heterosexism requires reducing our emphasis on competition, dominant masculinity, and status popularity, as well as democratizing our systems of rights and participation for sexual minorities and sexual diversity topics. When educators become more conscious of the learning opportunities we are already providing in schools - including their unintended consequences such as a climate of harassment and silencing - we can more effectively restructure those opportunities in line with our democratic values. 


\section{Diagram 1: DIMENSIONS OF MANAGING CONFLICT and VIOLENCE}

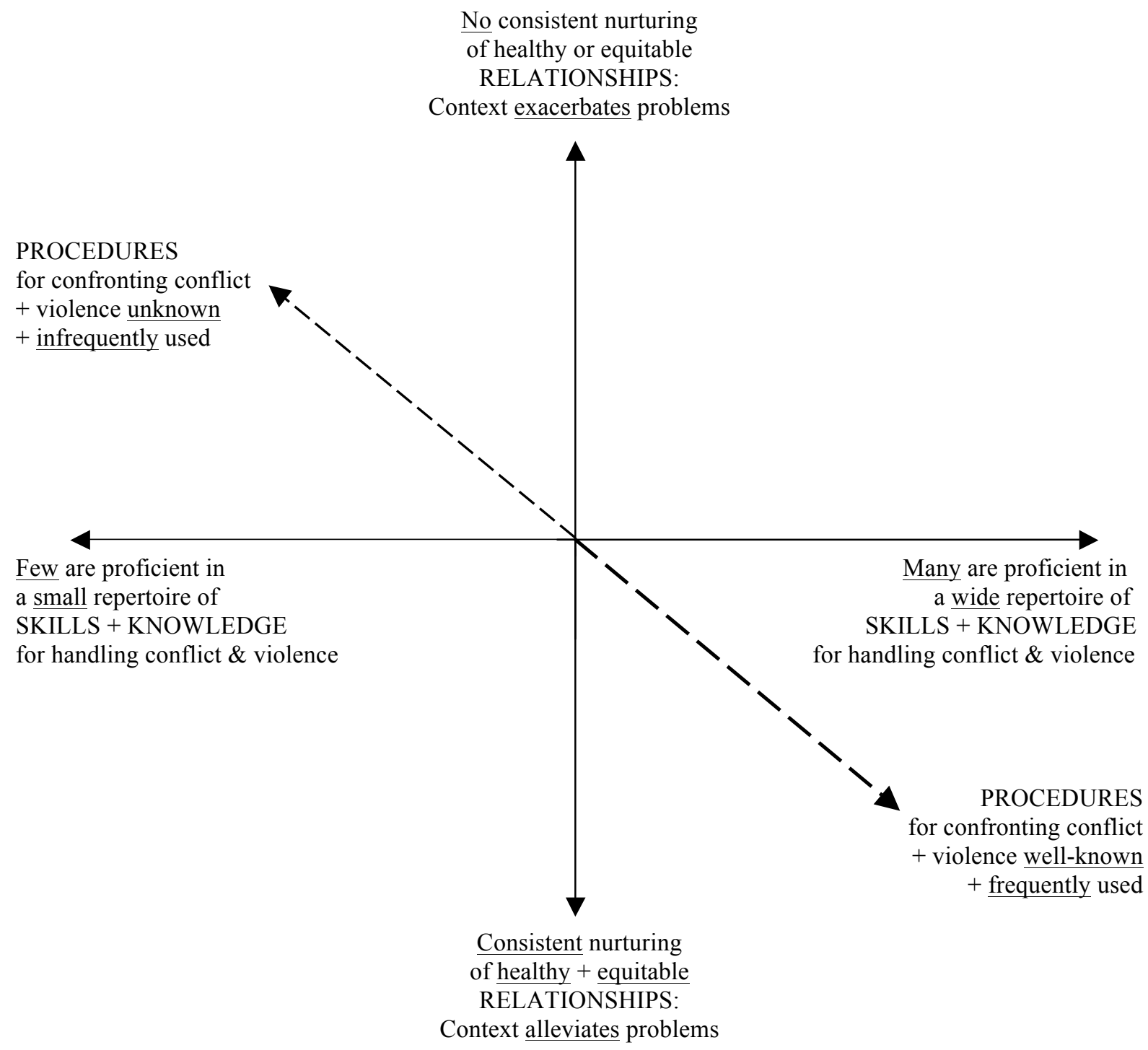




\section{$\underline{\text { References }}$}

Adams, M.L. (1997). The Trouble With Normal: Postwar Youth and the Making of Heterosexuality. Toronto: University of Toronto Press.

Apostol, C. (1998). Sexuality in children's literature. Ontario Public School Teachers Federation News, 12(2), 24-26.

Aronson, D. (1994). In the schoolyard at twilight: children with AIDS struggle for acceptance. Teaching Tolerance (Fall), 59-61.

Aronson, E. (2000). Nobody Left to Hate: Teaching Compassion after Columbine. NY: Worth Publishers.

Associated Press (2001). NEA drops homosexuality resolution. CNN.com Education (July 5) $<$ www.cnn.com/2001/fyi/teachers.ednews/07/05/homosexuality.nea.ap/index.html $>$

Avery, P., Sullivan, J. \& Wood, S. (1997). Teaching for tolerance of diverse beliefs. Theory Into Practice, 36(1), 32-38.

Ball, K. \& Martyn, P. (1999). Sexual harassment. Education Forum 25(1, Spring), $19-22$.

Bender, G. (2001). Resisting dominance? The Study of a marginalized masculinity and its construction within high school walls. In J. Burstyn et.al. (Eds.), Preventing Violence in Schools: A Challenge to American Democracy. Mahwah, New Jersey: Lawrence Erlbaum, 61-77.

Bergsgaard, M. (1997), Gender issues in the implementation and evaluation of a violence-prevention curriculum. Canadian Journal of Education 22(1), 33-45.

Bickmore, K. (1993a), Learning Inclusion/ Inclusion in Learning: Citizenship Education for a Pluralistic Society. Theory and Research in Social Education 21(4), 341-384.

Bickmore, K.(1996). Women in the world, women in the classroom: gender equity in the social studies. High School Journal 79(3), 231-241.

Bickmore, K. (1997). Preparation for pluralism: curricular and extra-curricular practice with conflict resolution. Theory Into Practice 36(1), 3-10.

Bickmore, K. (1999a), Elementary curriculum about conflict resolution: Can children handle global politics? Theory and Research in Social Education 27 (1), 45-69.

Bickmore, K. (1999b). Teaching conflict and conflict resolution in school: (Extra-) curricular considerations. In A. Raviv, L. Oppenheimer, \& D. Bar-Tal (Eds.), How Children Understand War and Peace. SF: JosseyBass, 233-259.

Canadian Press (2000). Students combat homophobia by forming gay-straight clubs. Canadian Press Newswire (March 9).

Chasnoff, D. \& Cohen, H. (1997). It's Elementary: Talking about Gay Issues in School (film). San Francisco: Women's Educational Media.

Cohen, R. (2001). A Peer mediation coordinator's dilemma: Should Angel be a mediator? The School Mediator (November and December), 1-3. <www.schoolmediation.com>

Connell, R.W. (1995). Masculinities. Sydney: Allen \& Unwin.

Dalton, D. (2000). Dangerous encounters: violence in the schools. Law Now 24(4, Feb/Mar), 23-24.

Davies, L. (2000). The civil school and civil society: gender, democracy, and development. In M. Arnot \& J. Dillabough (Eds.), Challenging Democracy. London: Routledge, 278-296.

Dietz, M. (1989). Context is All: Feminism and Theories of Citizenship. In J. Conway, S. Bourque, \& J. Scott (Eds.), Learning About Women. Ann Arbor: University of Michigan Press, 1989, 1-24.

Donahue, D. (2000). Lesbian, Gay, Bisexual, and Transgender Rights: A Human Rights Perspective. Amnesty International Human Rights Education Series, topic book 3. Minneapolis: Human Rights Resource Center humanrts@,tc.umn.edu

Duncan, N. (1999). Sexual Bullying: Gender Conflict and Pupil Culture in Secondary Schools. London:

Routledge.

EGALE. (1998). Bigots ban books. Equality for Gays And Lesbians Everywhere (EGALE), $<$ http://www.egale.ca>.

Elkind, D. (1995). School and family in the postmodern world. Phi Delta Kappan 77(1, September), 8-14.

Ellsworth, E. (1997). Teaching Positions: Difference, Pedagogy, and the Power of Address. NY: Teachers College Press.

Epstein, D. \& Johnson, R. (1998). Schooling Sexualities. Buckingham, UK: Open University Press.

Epstein, R. (1998), Parents' night will never be the same. Our Schools/ Our Selves 9(1), 92-117.

Fine, Melinda (1995). Habits of Mind: Struggling over Values in America's Classrooms. San Francisco: JosseyBass. 
Frank, B. (1996), Masculinities \& schooling: the making of men. In Epp, J.R. \& Watkinson, A.M. (Eds.). Systemic Violence: How Schools Hurt Children. NY: SUNY Press, 113-139.

Giese, R. (1998). Teach kids about sex now or suffer consequences later. Toronto Star (May 11), A13.

GLSEN (2001). Out at School. Teacher Magazine, (December). <http://www.teachermagazine.org>

Gordon, T., Holland, J., \& Lahelma, E. (2000a). From Pupil to citizen: a gendered route. In M. Arnot \& J. Dillabough (Eds.), Challenging Democracy. London: Routledge, 187-202.

Gordon, T., Holland, J., \& Lahelma, E. (2000b). Making Spaces: Citizenship and Difference in Schools. London: St. Andrews Press.

Gutmann, A. \& Thompson, D. (1996), The persistence of moral disagreement. In [authors] Democracy and Disagreement. Cambridge, MA: Harvard University Belknap Press, 11-51.

Hahn, C. (1996), Empirical Research on Issues-Centered Social Studies. In R. Evans \& D. Saxe (Eds.), Handbook on Teaching Social Issues. Washington, DC: National Council for the Social Studies (Bulletin \#93), 25-41

Harrington, C. (1999). Schools crack down on sexual harassment. Canadian Press Newswire (December 9).

Harris, M. \& Bliss, G. (1997). Coming out in a school setting: former students' experiences and opinions about disclosure. In Harris, M. (Ed.), School Experiences of Gay and Lesbian Youth: The Invisible Minority. The Haworth Press, 85-100.

Hoffman, L. (1995). Safe and supportive schools for gay, lesbian, and bisexual students: an idea whose time has come. The Fourth $R$ 56, 5, 13, \& 25.

Houser, N. (1996). Negotiating dissonance and safety for the common good: social education in the elementary classroom. Theory and Research in Social Education,24(3), 294-312.

Hydrick, C.J. (1994). The elementary school: censorship within and without. In Simmons, J. (Ed.), Censorship: A Threat to Reading, Learning, Thinking Newark, DE: International Reading Assn, 95-106.

Infantry, A. (1998). Schools get failing grade in AIDS ed. Toronto Star (November 24), A14.

Khayatt, D. (1997). Sex and the teacher: Should we come out in class? Harvard Educational Review, 67(1), 126-143.

Larkin, J. \& Staton, P. (1998). If we can't get equal, we'll get even: a transformative model of gender equity. Canadian Woman Studies 17(4, Winter), 16-22.

Lees, S. (2000). Sexuality and citizenship education. In M. Arnot \& J. Dillabough (Eds.), Challenging Democracy: International Perspectives on Gender, Education and Citizenship. London: Routledge, 259277.

Lenskyj, H. (1990). Beyond plumbing and prevention: feminist approaches to sex education. Gender and Education, 2(2), 217-230.

Lenskyj, H. (1994). Going too far? Sexual orientation(s) in the sex education curriculum. In Erwin, L. \& MacLennan, D. (Eds.), Sociology of Education in Canada. Toronto: Copp Clark Longman, 278-289.

Lesko, N. (2000). Making adolescence at the turn of the century: Discourse and the exclusion of girls. Current Issues in Comparative Education 2(2, April).

Luschen, K. (2001). Interrupting 'good' girlness: Sexuality, education, and the prevention of violence against women. In J. Burstyn et.al. (Eds.), Preventing Violence in Schools: A Challenge to American Democracy. Mahwah, New Jersey: Lawrence Erlbaum, 109-136.

Mandel, L. (1996). Adolescent gender identity and heterosexism in junior high school. Paper presented at Research on Women in Education conference, San Jose, CA (October 24).

Mansbridge, J. (1998). Feminism and democracy. In A. Phillips (Ed.), Feminism and Politics. New York: Oxford University Press, 142-158.

McCaskell, T. (1999). Homophobia: Violence in schools. Orbit 29(4), 20-21.

MacDonald, I. (1996), “Expanding the lens: Students' perceptions of school violence.” In Epp, J. \& Watkinson, A. (Editors). Systemic Violence: How Schools Hurt Children, 83-92.

Mlamleli, O., Mabelane, P., Napo, V., Sibiya, N., \& Free, V. (2000). Creating programs for safe schools: opportunities and challenges in relation to gender-based violence in South Africa. McGill Journal of Education 35(3, Fall), 261-277.

Noddings, N. (1992). Social Studies and Feminism. Theory and Research in Social Education. 20 (3, Summer) 230-241.

Ortner, S. (1996). Making Gender Boston: Beacon Press.

Osborne, K. (2000). Public schooling and citizenship education in Canada. Canadian Ethnic Studies 32(1), 837.

Osler, A. \& Starkey, H. (1998). Children's rights and citizenship: some implications for the management of 
schools. International Journal of Children's Rights 6, 313-333.

Paley, V.G. (1992). You Can't Say You Can't Play. Cambridge, MA: Harvard University Press.

Pharr, S. (1988). Homophobia: A Weapon of Sexism. Little Rock: Chardon Press/ The Women's Project.

Reiss, M. (1995). Conflicting philosophies of school sex education. Journal of Moral Education, 24(4), 371382.

Rich, A. (1979). On Lies, Secrets and Silence. NY: Norton.

Richardson, D. (1998). Sexuality and citizenship. Sociology 32(1), 83-100.

Rofes, E. (1995). Making schools safe for sissies. Rethinking Schools, 9(3), 8-9.

Roy, B. (1994). Some Trouble with Cows: Making Sense of Social Conflict. Berkeley: University of California Press.

Schissel, B. (1997). Blaming Children: Youth Crime, Moral Panics and the Politics of Hate. Halifax: Fernwood Publishing.

Scott, K. (1995). 75 years later: gender-based harassment in schools. Social Education, 59(5), 293-297.

Sears, J. (1992). Dilemmas and Possibilities of Sexuality Education: Reproducing the Body Politic. In J. Sears (Ed.), Sexuality and the Curriculum: the Politics and Practices of Sexuality Education. NY: Teachers College Press, 7-33.

Shakeshaft, C. \& Mandel, L. (1997). Boys call me cow. Educational Leadership (October), 22-25.

Stein, N. (1995). Sexual harassment in school: the public performance of gendered violence. Harvard Educational Review 65(2, Summer), 145-161.

Tannen, D. (1998), "The Roots of debate in education and the hope of dialogue." In [author] The Argument Culture: Stopping America's War of Words. Toronto: Random House, 256-290.

Teaching Tolerance (1994). Whose news? Student journalists examine gay rights; community response is shock, anger. Teaching Tolerance 3(2, Fall), 24-27.

Weikel, B. (1995), 'Girlspeak' and 'Boyspeak': Gender Differences in Classroom Discussion. In J. Kleinfeld \& S. Yerian (Eds.), Gender Tales: Tensions in the Schools (7-11). NY: St. Martin's Press.

Wessle, S. (2000), Sticks and Stones. Educational Leadership 58(4) (December/January) $<$ www.ascd.org/readingroom/edlead/0012/wessler.html $>$

Wyness, M. (2000). Sex education and the teaching of citizenship: towards a more inclusive conception of childhood. Pedagogy, Culture and Society 8(3), 347-363. 